\title{
Eutrophication of the Vistula Lagoon Water and Integrated Management Methodology of the Coastal Zone in the Region
}

\author{
Vasilina N. Medvedeva \\ Immanuel Kant Baltic Federal University, Atlantic Research Institute of \\ Marine Fisheries and Oceanography \\ Olga Y. Nizhnikovskaya \\ Immanuel Kant Baltic Federal University, Atlantic Research Institute of \\ Marine Fisheries and Oceanography \\ Sergey V. Aleksandrov \\ Immanuel Kant Baltic Federal University \\ Vladimir A. Gritsenko \\ Immanuel Kant Baltic Federal University \\ Valeriy A. Funtikov \\ Immanuel Kant Baltic Federal University, *Corresponding email: VFuntikov@kantiana.ru
}

Doi:10.5901/mjss.2015.v6n6s7p200

\section{Abstract}

The study provides substantiation of the use of integrated management methodology of the coastal zone, in order to provide monitoring observation of the coastal waters of the Kaliningrad region in terms of water quality, as well as complement traditional instrumental measurements of the marine environment parameters by means of various satellite programs.

Keywords: integrated management, coastal zone, water eutrophication

\section{Introduction}

Globalization processes and ongoing crisis phenomena in many states' economic development require new and additional opportunities for sustainable development of the Kaliningrad region as well. Lack of any region's growthrelevant domestic resources prompted the RF government to take a decision on inclusion of the tourism component in the priority development directions of the Kaliningrad region.

It is well known that infrastructure and the potential of beach, rehabilitation and spa tourism are quite developed in our region, but their further growth will require significant investment. However, two shallow lagoons and coastal sea areas of the Baltic Sea in the region makes water tourism promotion quite promising. 'Navigation rules for sailing and pleasure boats under foreign states' flags along internal waterways of the Russian Federation' approved in May 2012 contributed to the development of this type of tourism. Opening of the indicated areas for free navigation significantly expanded the potential of tourism industry development, mutually beneficial for Poland, Lithuania and Russia. It is also evident that an important development factor for all types of recreation at and on the water is water quality of corresponding water areas.

Under the current conditions, the use of coastal waters cannot be regulated without regard to the integrity and mutual influence of any type of natural resource management. This can be assisted by implementing the methodology of coastal zone integrated management (CZIM). The methodology is based not on state but ecosystem boundaries (Serditova, 2006). Moreover, conflicts between various categories of users become more obvious and expanded with increasing population density and the degree of natural resources use. 
Let us now consider the significance of the above-mentioned provisions by the example of the Vistula Lagoon. Successful use of all its resources depends on the water quality largely defined by eutrophication of its water. According to GOST 17.1.1.01-77, water eutrophication is increasing of biological productivity of water bodies as a result of accumulation of nutrients in the water under the influence of anthropogenic or natural factors. Indicator of water eutrophication and pollution is information about the concentration of chlorophyll "a" in the water as an indicator of phytoplankton abundance and water 'blooming'. Assessment of the ecological status and monitoring of this indicator in the Baltic Sea are prescribed by the Water Directive and Marine Strategy of the European Union (Directive 2000/60/EC, Directive 2008/56/EC). According to these normative documents, coastal countries, including the Baltic Sea countries, based on the analysis of long-term data should establish regional systems of water quality classification. This will enable them to further pursue legitimate environmental policy with the view of improving the status of aquatic ecosystems (Directive 2000/60/EC).

\section{Practical Research of Water Eutrophication}

To assess the trophic status and water quality of the Vistula lagoon, indicators of primary production of phytoplankton, concentration of chlorophyll "a", ratio of other pigments (chlorophyll "b", "c") and pigment indices are usually used. Low values of carotenoids and chlorophyll ratio are considered as indicators of physiological well-being of phytoplankton communities. This allows using pigments and pigmenting indices as an indicator of the state of phytoplankton under different environmental circumstances (Mineeva, 2004). These parameters have been studied in the Laboratory of Hydrobiology of the Atlantic Research Institute of Marine Fisheries and Oceanography (AtlantNIRO) for the past 25 years.

Monitoring of the Vistula Lagoon is carried out at 9 stations, the location of which corresponds to the hydrological and hydrochemical division of the Russian water area into 4 sub-areas, including: Eastern region (stations № 1, 2, 3, 5) a shallow area, which is heavily dependent on the river flow (Pregel River) and exposed to pollution from the watershed and wastewater of Kaliningrad; Primorskaya Bay (station № 4) is a shallow, fairly isolated area that contributes to the concentration of pollutants delivered through the Kaliningrad cleaning channel, Primorskaya River and from Primorsk; Baltic region (stations № 9, 10) - located in the heart of the Russian part, under the influence of marine waters inflow through the strait; Central region (station № 6, 7) - the most extensive, the northern part is located within Russia, the southern - within Poland, where hydrological and hydrochemical conditions are determined by cumulative influence of marine water from the Baltic area and desalinated water running from the Elblag Bay, located in the Polish part.

Long-term monitoring of the Vistula lagoon's water area (Aleksandrov, 2010) showed significant spatial and seasonal variation of basic hydrological parameters (temperature, salinity), nutrients and chlorophyll concentration, etc. (see Fig. 1, 2).
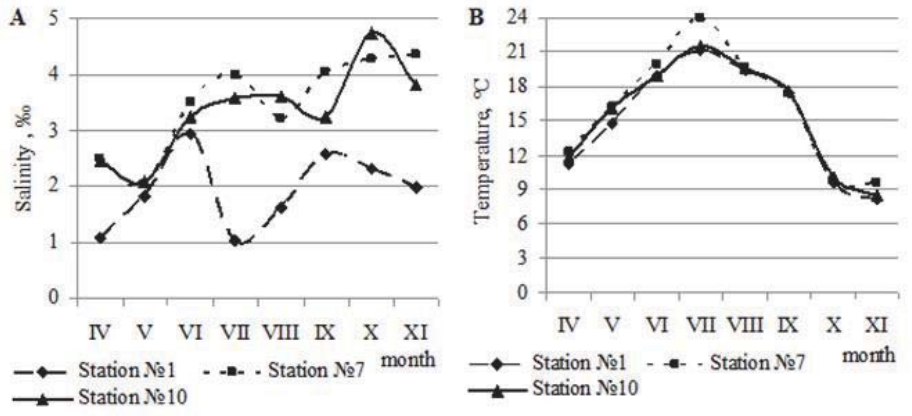

Figure 1. Seasonal variability of salinity (A) and water temperature $(B)$ of the Vistula Lagoon in different sub-areas in 2011 


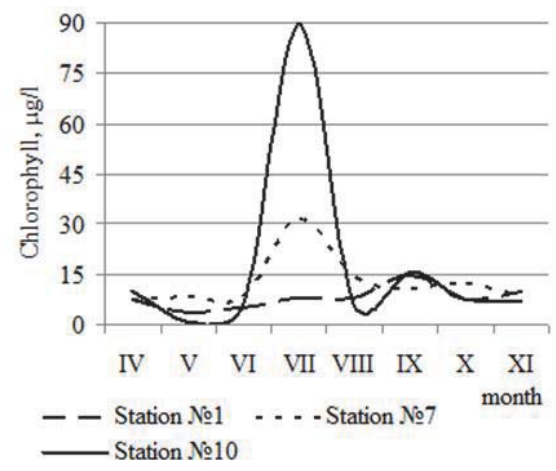

Figure 2. Seasonal variability of chlorophyll "a" concentration in the Vistula Lagoon in different sub-areas in 2011

The Vistula Lagoon is shallow water and well-mixed. However, during the summer period, "blooming" of Cyanobacteria can be observed at certain sites of the lagoon. This results in the accumulation of phytoplankton in the surface layer and local variations of the eutrophication level of its waters. Considerable seasonal and long-term variation of primary production of phytoplankton is conditioned by hydrochemical and hydro-meteorological phenomena (Aleksandrov, 2010).

High concentration of chlorophyll "a" most often occurs in the Primorskaya Bay where nutrients are delivered through the collector of Kaliningrad, as well as in the eastern part of the Lagoon, where nutrients from the watershed of the Pregel River are poured (Fig. 3). Throughout the year, elevated concentration of mineral and organic nitrogen and phosphorus there that stimulates phytoplankton development.

Lower concentration of chlorophyll "a" has been recorded in the western part of the Vistula Lagoon (Fig. 3). The abundance of phytoplankton in the western area is decreased under the influence of low-productive sea water coming through the Baltic Strait.
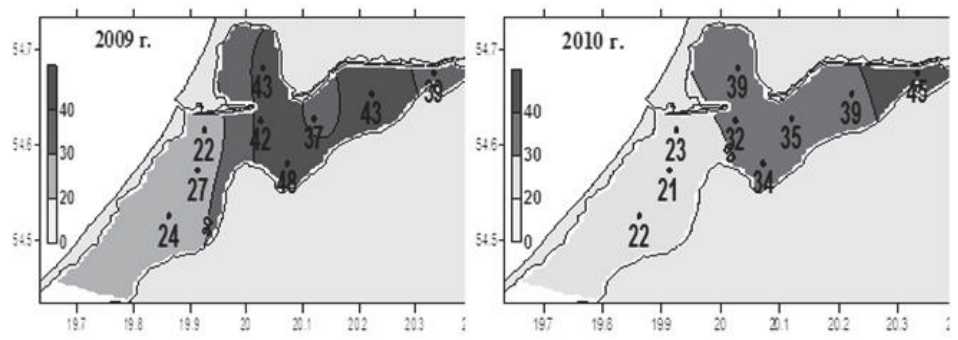

Figure 3. Average annual concentration of chlorophyll a $(\mu \mathrm{g} / \mathrm{l})$ in the surface water of the Vistula Lagoon in 2009 and 2010

Primary production values have similar distribution with the concentration of chlorophyll "a". It is characterized by the largest values in the eastern area and the Primorskaya Bay. The lowest primary production throughout the year has been recorded in the western area of the Vistula Lagoon, corresponding to the lowest development of phytoplankton in the water area. In summer, primary production of phytoplankton in the Vistula Lagoon exceeds the bacterial mineralization of organic matter in the water column (on the average 50\%). This can lead to its accumulation in the water, bottom sediments and further eutrophication of the water body. However, due to intensive water exchange with the sea, a significant part of the organic substance not exposed to d mineralization in the lagoon, is probably carried through the sea strait.

The concentration of chlorophyll "a" in the Vistula Lagoon has been studied for 25 years, and "b" and "c" chlorophyll - since 2009. During the research period, the highest concentration of chlorophyll was usually observed in mid-spring and, especially, in summer, during rapid spring development of diatoms and summer "blooming" of Cyanobacteria. 
The ratio of chlorophyll "a", "b" and "c" varies significantly during the year. Seasonal dynamics of chlorophyll "b" and "c" is characterized by the maximum concentration (5-29\% and 11-45\%) in April-June till the beginning of "blooming" of Cyanobacteria. In summer, when the bloom Cyanobacteria is observed, chlorophyll "b" and "c" is significantly reduced to $3-5 \%$ and $2-10 \%$, whereas the concentration of chlorophyll "a" increases significantly. Therefore, the increase of chlorophyll "a" as a result of mass development of Cyanobacteria can be an indicator of eutrophication of the Vistula Lagoon.

\section{Trophic Status Assessment of the Vistula Lagoon Water}

The most developed classifications of eutrophication and water quality for the Baltic Sea are currently used in Sweden and Finland (Vuoristo, 1998; Wasmund, 1990; Wasmund et al., 2001).

Quantitative assessment of the intensity of biological productive processes and, especially, primary production of phytoplankton was the basis for the trophic classification of water bodies. A modern system of water body typology was built around it. Evaluation of the summer values of primary production and chlorophyll "a" concentration was wide-spread. The Vistula Lagoon is characterized by rather significant variability of water eutrophication indicators that can be traced based on the data of 2009-2011.

In particular, 'blooming' of Cyanobacteria was observed in summer 2009 in the central part of the Vistula Lagoon. Values of chlorophyll "a" corresponded to hypertrophic status (> $100 \mu \mathrm{g} / \mathrm{l})$, and in the Primorskaya Bay and the Kaliningrad Gulf were close to this level. In the western part of the Vistula Lagoon, exposed to the low-productive sea water coming through the strait, the concentration of chlorophyll "a" was significantly lower and corresponded to the eutrophic level. Summer 2009 was marked by one of the highest values of primary production due to the combination of favorable conditions (intense water heating, calm weather) for the development of Cyanobacteria. In summer 2010, the Vistula Lagoon was marked by the level of phytoplankton abundance and production comparable to the average annual. The concentration of chlorophyll "a" $(26-79 \mu \mathrm{g} / \mathrm{l})$ as an indicator of phytoplankton abundance corresponded to the eutrophic state (10-100 $\mu \mathrm{g} / \mathrm{l})$. Primary production throughout the water area of the Vistula Lagoon was typical of the hypertrophic status of the aquatic ecosystem $\left(>2,0 \mathrm{~g} \cdot \mathrm{m}^{-2} \cdot \mathrm{day}^{-1}\right)$. The values obtained correspond to the long-term average of primary products according to the literature data and research results.

In summer 2011, the level of phytoplankton abundance and production was below average. The concentration of chlorophyll "a" (5,4-31,5 $\mu \mathrm{g} / \mathrm{l})$ was consistent with the mesotrophic /eutrophic state (1-10 $\mu \mathrm{g} / / \mathrm{l} / 10-100 \mu \mathrm{g} / \mathrm{l})$. Production and abundance of phytoplankton in the Vistula Lagoon due to the lack of nutrients limitation are mainly determined by temperature conditions. Dynamics of water temperature variation in the Vistula Lagoon is characterized by smooth increase from March to May and sharper seasonal rise in summer. The optimum temperature for maximum development of phytoplankton in the Vistula Lagoon is above $20^{\circ} \mathrm{C}$ (Aleksandrov, 2010). Analysis of monitoring observation results in 2009-2011 enabled us to obtain productivity indices of phytoplankton for two possible scenarios of functioning of the Vistula Lagoon ecosystem. 'Hyperblooming' of Cyanobacteria in 2009 or absence of algae "blooming" in 2011 made it possible to cover a significant section of the range of potential variability of the eutrophication process for the Vistula Lagoon. The obtained data of dependency between the abundance of phytoplankton (chlorophyll "a"), primary production and temperature attest to the need for comprehensive analysis of the environmental factors determining the structure and productivity of phytoplankton.

\section{Possibilities of Using Satellite Observation for the Vistula Lagoon}

The use of satellite information is the most available and effective for performing operational monitoring of water areas and obtaining objective information in order to make management decisions. This is due to the lack of operational contact research of the lagoon's water area.

Satellite scanning technology of the surface sea layer provide for regular obtaining of required thermodynamic, optical, water level and meteorological parameters with high spatial and time resolution (from $1 \mathrm{~m}$ to $1 \mathrm{~km}$ and from several hours to 10 days). This makes satellite-based monitoring the most important control method of the water ecological status. Comprehensive monitoring of sea water is based on digital data receipt from different radiometers, scanners, spectrometers, radars, altimeters and scatterometers. These devices are installed on the satellites of NOAA, Terra, Aqua, TOPEX/Poseidon, Jason, ENVISAT, Radarsat, QuikSCAT, Landsat, IKONOS, SPOT, QuickBird, etc. The sensors obtain information about morphometric characteristics of a water body, temperature field, suspended solids, chlorophyll concentration, water 'blooming' and other optical characteristics of the water surface, oil pollution, as well as changes of the sea (lake) level, variability of currents, wind speeds and wave heights (Vignudelli et al., 2011). For the 
Vistula Lagoon, the data describing water thermohydrodynamics, change of level, turbidity and color of water can be studied using survey data of high, detailed resolution of optical and infrared ranges, as well as the radar survey data. Existing active and passive sensors operating in the visible infrared and microwave areas of the electromagnetic spectrum enable us to specify four main parameters of sea water - colour, temperature, height and roughness of the sea surface (Kashkin \& Sukhinin, 2001). The specification is performed using IR-radiometers and spectroradiometers of satellites AVHRR/NOAA TRACK/ERS-1-2, AATSR/Envisat, MODIS/Terra, Aqua, TMI/TRMM, etc.; scatterometers and microwave radiometers of satellites SCAT/ERS-1-2, NSCAT/ADEOS, QuickSCAT/SEAWIND, SSM//IDMSP, etc.; manyzoned scanners and cameras of satellites CZCS/Nimbus, SeaWiFS/SeaStar, MERIS/Envisat, MODIS/Terra, Aqua, ADEOS, etc.

All these remote sounding opportunities provide for using relevant data arrays for any of monitoring tasks of the water area state. However, the satellite data cannot completely replace the entire volume of conventional observations and should be regarded as one of the types of new information. This type of research substantially enhances the quality of information support of forecasting, and is used in conjunction with traditional forecasting information types.

\section{Conclusion}

The existing monitoring system of water eutrophication of the Vistula Lagoon based on data collection according to hydrometeorological, hydrochemical and hydrobiological indicators (chlorophyll concentration and primary production) provide for carrying out further comprehensive analysis of the lagoon's water quality. Measured indicators of the environment help determine the structure and productivity of phytoplankton in the brackish lagoon ecosystem, as well as simulate its response to various global and regional changes.

However there are only 9 monitoring research stations AtlantNIRO with a monthly observation period in the water area of the Vistula Lagoon. More detailed spatial and temporal data on a number of proxy indicators characterizing water eutrophication processes (thermohydrodynamics, water turbidity and colour) can be obtained with the involvement of regular satellite observations.

Traditional systematic instrumental observations have shown that phytoplankton blooming is influenced by a number of parameters, such as salinity, water enrichment with nutrients, water surface heating, etc. Correspondingly, inflow of the sea water from the Baltic Sea into the Vistula Lagoon is important for the ecosystem as a whole. The inflow and its dynamics in time and space can be possibly traced based upon satellite data (Nizhnikovskaya \& Medvedeva, 2013; Vinogradov, 1984).

Monitoring observation with the use of contact and remote measurements clearly testifies in favor of the need of their joint use. The combination of already performed field observations with archival data of satellite survey of the water area of the Vistula Lagoon will enable to obtain a holistic view of variability, for example, water eutrophication process.

It is also evident that assessment of primary production and phytoplankton abundance (chlorophyll concentration) as indicators of eutrophication of the Vistula Lagoon water should be included in the list of parameters for an integrated coastal zone management (ICZM) in the region. Classic field monitoring does not solve the problem of spatial and temporal details of the observations. Therefore, satellite observations are necessary as a natural component of ICZM. The existing monitoring system, available material base and qualification of specialists create favorable conditions for practical application of ICZM methodology in the process of planning development of the regional natural and socioeconomic system of the Vistula Lagoon.

\section{References}

Aleksandrov, S.V. (2009). Assessment of the environmental state of the South-Eastern part of the Baltic Sea with the use of hydrobiological and hidrochemical data. Commercial-biological researches of AtlantNIRO in 2006-2007. Vol. 1. The Baltic Sea and lagoons (pp 217-227). Kaliningrad: AtlantNIRO.

Aleksandrov, S.V. (2010). Primary production of phytoplankton in the Curonian Lagoons and Vistula Lagoons of the Baltic Sea. Kaliningrad: AtlantNIRO.

Directive (2000). Directive 2000/60/EC of the European Parliament and of the Council of 23 October 2000 establishing a framework for Community action in the field of water policy. Official Journal $L 327,22 / 12 / 2000$.

Directive (2008). Directive 2008/56/EC of the European Parliament and of the Council of 17 June 2008 establishing a framework for community action in the field of marine environmental policy. Official Journal of the European Union L 164, 25/06/2008.

Kashkin, V.B., \& Sukhinin, A.I. (2001). Remote sensing of the Earth from space. Digital processing of images: Tutorial. M.: Logos.

Mineeva, N.M. (2004). Plant pigments in the water of the Volga reservoirs. M.

Nizhnikovskaya, O. Y., \& Medvedeva, V. N. (2013). Satellite data as a necessary element of satellite observations of the Vistula 
Lagoon's state. Proceedings of the $5^{\text {th }}$ International scientific conference "Present-day geoecological problems" (pp. 167-171). Vladimir, 2013.

Serditova, N.E. (2006). The economy of natural resource management: ecological and economic aspect. St. Petersburg.

Vignudelli, S., Kostianoy, A.G., Cipollini, P., \& Benveniste, J. (2011). "Coastal Altimetry". Springer-Verlag, Berlin, Heidelberg, New York. Vinogradov, B.V. (1984). Aerospace monitoring of ecosystems. M.: Nauka.

Vuoristo, H. (1998). Water quality classification of Finnish waters. European Water Management, 1(6). 35-41.

Wasmund, N. (1990). Characteristics of phytoplankton in brackish waters of different trophic levels. Limnologica, 20, 47-51.

Wasmund, N., Andrushaitis, A., Lysiak-Pastuszak, E., Müller-Karulis, B., Nausch, G., Neumann, T., Ojaveer, H., Olenina, I., Postel, L. \& Witek, Z. (2001). Trophic status of the southeastern Baltic sea: a comparison of coastal and open areas. Estuarine, Coastal and Shelf Science, Vol. 53, 849-864. 